\title{
FinCraft: Immersive Personalised Persuasive Serious Games for Financial Literacy Among Young Decision-Makers
}

\author{
Aldrich Rasco \\ University of Auckland \\ a.rasco@auckland.ac.nz \\ Gabrielle Peko \\ University of Auckland \\ g.peko@auckland.ac.nz
}

\author{
Johnny Chan \\ University of Auckland \\ jh.chan@auckland.ac.nz \\ David Sundaram \\ University of Auckland \\ d.sundaram@auckland.ac.nz
}

\begin{abstract}
FinCraft is an open source gaming platform to enhance financial literacy. Research has shown a growing concern for financial literacy and financial decision-making across several age groups and interventionist programme methods. However, very few focused on the youth demographic specifically. Fewer, considered fun and sustainable means of financial literacy enhancement. In a day and age of instant gratification, people gravitate towards familiar and engaging content. In this paper, we posit starting financial literacy enhancement early - during the teenage years of individuals, so secure saving and spending habits can be adopted prior to adult years and responsibility. Through gamification, FinCraft aims to bridge the familiarity and engagement gap that makes financial literacy, an unexplored, significant part of growing up. We propose various conceptual and system artefacts at the intersection of serious games and learning analytics for financial literacy.
\end{abstract}

\section{Introduction}

We are all decision makers. Decisions shape the consequences of events. In particular, the significance of financial literacy and financial decision-making tends to grow over time. As we grow older, our accumulated knowledge and behaviour in saving and spending, will determine the situations we can and cannot afford to be in. To the young, this is of a lesser concern, since parents and caregivers undertake most of the financial decision-making responsibilities. In this practical context, there are legitimate questions to explore: What good would it be if young people are capable of becoming good financial decision makers? How can we convince youth to adopt secure and effective decision-making processes to safeguard their future? How can we get youth to start thinking about retirement planning at an early age?

The motivation of this paper is to further the conversation about financial literacy and decisionmaking in languages that the instantly gratified speak games, gamification, design and narratives. Through their captivating, immersive, easy, fun and personal nature, several artefacts are presented in order to draw the financially naive closer to a more sustainable and thoughtful means of spending and saving money. The following section delves into the literature on learning, financial literacy and decision making among youth. Section 3 focuses on the adapted design science method and the learning system dynamic that we propose. Sections 4 to 6 present the conceptual foundations of our approach (FinCraft) to design immersive, personalised, persuasive, serious games for financial literacy among young decision makers. Sections 7 and 8 present the FinCraft system framework and architecture respectively. Section 9 concludes the paper.

\section{Literature review}

Learning techniques, styles, methods, and systems through the years pave the way for rethinking ways of enhancing financial literacy. Technology, as a key component for vastly accelerating our learning capabilities and capacities have been a contemporary subject in research. Literature unanimously points toward the unparalleled advantages of adapting technology and its implications for us, learners, as well as teachers and the teaching pedagogical system in place $[4,6,40,52,53,54]$. The growth of literacy has been a by-product of the dynamics within this system which encourages contemporary research to conceptualise models of improving literacy through technology. Roblyer's [48] discussion of integrating technology with learning is especially useful for highlighting the intrinsic value of constructivist learning theories and its suitability in applying the technologies we have. This comparison is made in the fundamental discussion between constructivist, who defines learning as constructed knowledge, and 
objectivist, who sees it as transmitted knowledge. Ubiquitous smart technologies are especially useful for individually constructing knowledge. This case is very symbolic for this day and age's growing appreciation for constructivist approaches in learning. Moore and Kearsley [42] especially highlight the shift of distance education learning institutions towards more accessible and ubiquitous learning institution types from correspondence, radio, and television as the predecessors to more advanced versions such as teleconferencing and the internet/web. It is notable that as learning methods and mechanisms improve, so does our ability to partake in distance education in the most convenient way possible. So while learning mechanisms change, the teaching side of the system has to adapt to benefit the constructivist advantage. In Bang \& Dalsgaard's [4] study they argue that the facilitation of E-learning should shift its focus to learning activities. In their discussion of Leon'ev's dimensions of activity framework and Bateson's five levels of learning, they point out that as the level of learning consciousness increases so does the task's propensity to require collaboration. Alternatively, in lower levels of learning consciousness, tasks require simple cooperation. The crux of the discussion is that since higher levels of learning consciousness and collaboration are expected from students, it is best to augment E-learning with more complex activities. In this paper, we argue that such complex activities can be articulated and manifested through gamification. The next logical step of adapting constructivist ideas is to make education fun and entertaining. Since gamification can allow for such complex activities, it can very much activate higher levels of learning consciousness and subject the user to multiple iterations of single loop, double loop and triple loop learning cycles [19, 57]. In learning literature, learning cycles pertain to the iterations of learning which demonstrate incremental learning, and multiple levels of reflection and evaluation regarding the nature and outcomes of the learning process. With relation to financial literacy and financial decision-making enhancement, activating deeper levels of learning consciousness and iterative learning cycles in the user is an effective way of constructing knowledge and forming literacy. Resulting in a deeper understanding can bridge effective decision-making habits and tendencies.

Literature clearly states that low levels of financial knowledge, or financial illiteracy, is associated with poor financial outcomes [12, 23, 31, 33, 34, 37]. The empirical evidence in Lusardi's survey [37] suggests that planning is an important determinant of wealth accumulation. Financially literate people are more inclined to plan and are more likely to accumulate wealth fit for retirement. Furthermore, planners are associated with more satisfying retirements, perhaps due to accumulating higher financial resources and a higher likelihood to invest. Conversely, financial illiteracy is more noticeable among low income, low education and low wealth groups.

According to $\mathrm{Xu} \& \mathrm{Zia}[60]$, the term financial literacy can encompass several concepts ranging from financial awareness and knowledge, including financial products, institutions, and concepts; financial skills, such as the ability to calculate compound interest payments; and financial capability, in terms of money management and financial planning. While we grant that it could be easy to grasp what financial literacy is referring to, research has shown several treatments of its scope. Huston's [26] summarises that financial literacy studies cover: money basics, borrowing, protecting assets and investing. Most studies show an appreciation of money basics but only a few are comprehensive at covering all four areas. With this in mind, research in the field tends to show some biases, or choice over the perspective with which financial literacy is addressed. This is paradigmatic of the inconsistent interpretation of the ontology of financial literacy. Remmele [46] is right in suggesting that some financial objects within its literacy are incomprehensible, which subjects its overall scoping or interpretation to some political space debating its predetermined stance. An example of such reasoning can be applied to money, which he claims is a social arrangement. Our interactions and encounters of money variate the corresponding emotional and social value we give to our spending currency. In application to research, claiming that an individual is financially illiterate simply because of high expenditure and low saving abilities does not always necessarily link to low cognitive knowledgeability within the domain. Remmele [46] advises, that while it is not difficult to understand the precepts of financial literacy, we should be careful of the potential biases or boundedness embedded within the research. Hence, rigorous research in this area tends to not only aim to improve cognitive ability or upskill standard knowledge, but it also pays respects to accepted formal literacy measures with insight over potential biases.

Throughout the years, the idea of financial literacy tends to overlap with financial capability and financial decision-making. Atkinson et al [2] suggest that the term financial literacy does not go beyond basic skills and understandings, therefore capability could be a more suitable term. They identify four domains of financial capability: managing money, planning ahead, choosing product and staying informed. Alternatively, financial decision-making in literature is a term that is more often used as part of managerial decision- 
making. While the focus of this paper is to outline the importance of good decision-making amongst youth, it is important to denote that we are mostly concerned about their financial literacy and capability rather than any decision related to management. Atkinson et al. [2] denote that those who are financially capable could employ reasonable and logical financial decisionmaking. They are able to commit to simple decisions such as choosing to make ends meet and having some provision over a loss of income. Literacy is very clear in emphasising the linkage between financial literacy and effective financial decision-making.

Knowledge is generally viewed as a principal source of value creation $[13,39,56]$. The accumulation of such knowledge applies in the pursuit of financial literacy in many individuals and communities. Several studies focus on applying such intervention-based strategies to improve financial literacy $[6,16,24,29$, $43,52,62]$. While most of the research follows a traditional approach in terms of improving financial cognitive abilities, only a few focus on youth $[5,22$, $27,28,32,45,52]$. Financial literacy enhancement in young people is an interesting scenario. Their exposure to financial decision-making is raw and is significantly influenced by their socio-economic household status.

To cultivate good financial decision-making in youth it is important to study the most effective means of communicating habits to them. Sefton-Green [63] argues that youth appropriation in digital culture makes it a comfortable platform for them to use. When comparing to general wisdom, this rings true as youth activity is dominated by digital multimedia interaction. What better teacher of financial decision-making could there be, apart from the primary recipient of youthful attention - digital technology? Gefen's study [18] of familiarity and trust in e-commerce identifies two key motivations of people to use a particular platform. Firstly, while youth are naturally comfortable with the use of digital technology, familiarity and trust towards the platform are still critical aspects affecting their motivation to use it. Secondly, in order to use digital technology as a financial literacy and decision-making enhancement tool, the platform needs to be optimised so that it conveys a level of familiarity and trust. Within the context of a gaming solution therefore, apart from its intrinsic engaging quality, it must win the attention of youth by being sufficiently familiar and trustworthy to be able to influence their financial literacy and decision-making capabilities. Design science is an appropriate research method to realise such a solution.

Learning is a key component of FinCraft and goes beyond its gaming capabilities. It involves the idea of optimising learning for the user in many ways to maximize the value that they gain. Several studies on serious games present the ease and effectiveness with which games are able to educate, train and inform learners [36, 38, 47]. Playing games is intrinsic to humanity. Research shows that serious games are effective messengers of information and skill development [55]. Central to this value is the positive cognitive and motivational effects it brings about during critical thinking [50]. As game-based learning research flourished in the $21^{\text {st }}$ century so did the use of serious games in high-stakes real life applications [3, 9]. The motivational and learning effort that can be found in these situations is interestingly similar to the tenets of learning analytics. Several ideas such as leveraging human judgement, designing adaptiveintelligent curriculums and empowering instructors and learners in education all fall under the same motivation of optimizing learning for the better [41]. In this paper, we argue that there is a huge gap with which the intersection of all three ideas can be summarised and be validated through good design. FinCraft will contextualise these ideas within the realm of financial literacy, where the empowerment of learning can be improvement through serious games and learning analytics.

\section{The design science study}

To truly capture the motivation of youth in terms of familiarity and trust, some level of purposed design is appropriate to captivate the desired 'instant' attention. Consequently, when youth is engaged, gamification can be utilised to influence their financial decisionmaking in a persuasive and immersive way. An adaptation of the design science research process proposed by Peffers et. Al [44] is used (Figure 1). In the first step, we synthesise literature to identify the problems and practical motivation for this study. The crux of the research problem is the evidential naive financial decision-making common amongst youth. Engagement is a key issue, and through literature we know that bolstering youth's familiarity and trust can improve the motivation to engage with technology. Hence, we are primarily motivated to use gamification as a critical design tool for financial literacy engagement because of its intrinsic engaging qualities and also its capacity to handle financial literacy modules with some level of familiar and trustworthy content. The objectives of the solution are then moulded around the development of a personalisation tool. While games are already intrinsically engaging, further configuration based on personal characteristics adds another level of familiarity and trust.

The personalisation tool will be largely instrumental in bridging familiarity towards the content as well as providing a base range of archetypes from which learning analytics can be developed. Learning analytics 
could affirm the archetypal personalisation. It gives us developmental clues that helps us to further configure, adapt and evolve the base game to truly match user requirements to their financial literacy needs and preferences. To execute the solution, it needs to be applied in a financial literacy intervention programme where the prototype game will be piloted for demonstration. Finally, the prototype will be evaluated against the feedback of financial education experts.

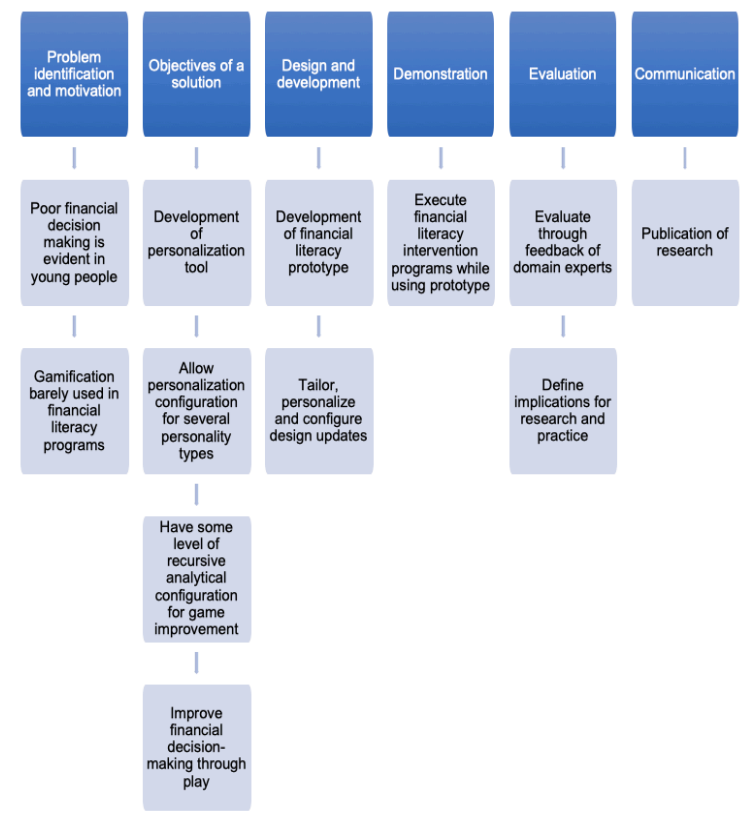

Figure 1. Design science process

\section{Enhancing financial literacy}

Pang's [43] conceptual approach to enhancing financial literacy of young people is very important from two perspectives. First, he sees enhancement is achievable through fundamental teaching, and its pedagogical success can be accentuated with various modalities such as tasks, illustrations and explanations. Second, he highlights the importance of learning-tolearn effects. Since financial literacy is largely applicable to real life, learning-to-learn financial components individually is crucial for sustainable knowledge application and ongoing financial awareness. Although we agree with Pang's findings, we suggest that this is simply the start to improving the overall process of enhancing financial literacy. In knowledge sharing, decision-making and learning literature, we find that motivation, internalisation, habit formation and intelligence impact the many variables when knowledge is being shared and eventually learned $[11,15,17,51]$. Figure 2 is a summary of findings regarding the between decision-making and learning, and the fundamental solution being proposed in this paper - gamification. This can also be applied to Pang's [43] idea of financial literacy enhancement, which can be very useful in intervention-based schemes. It is generally accepted in the literature that the elements of fun achieved by games and gamification positively affect the motivation of students, especially youth [7]. Over the years, several studies corroborate the idea that it is beneficial to use gamification for motivation and educational objectives inside and outside the classroom [8, 14, 20, 25, 49]. Following Pang's logic, games is thus an ideal choice for variating the fundamentals of teaching and enhancement of financial literacy. Yee's study [61] is useful for suggesting that motivation for gaming is strong for several age groups, especially those in their schooling years. This underlines the suitability of utilising gamification as an educational tool on financial literacy for youth. Gamification should strike some level of immediate familiarity for youth due to their familiarity with play and gaming dynamics [61]. The improvements in familiarity and trust should help increase motivation, result in better learning that then improves insight, problem solving ability, internalisation of opportunities and intelligence. All of these have a positive effect on decision-making quality and habit formation $[1,15,17,21,58]$.

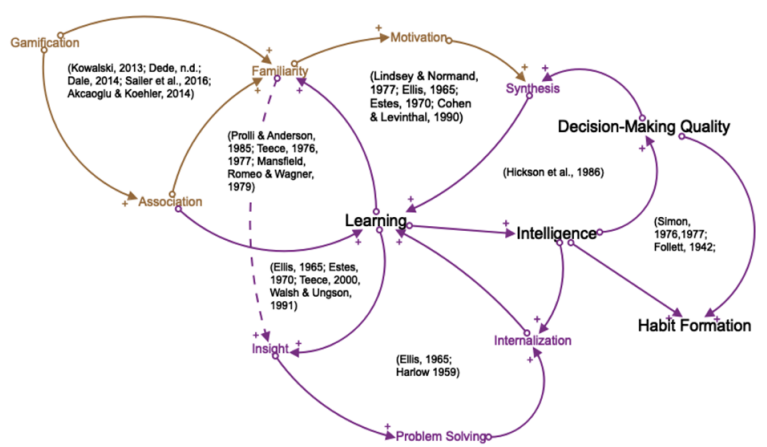

Figure 2. The learning system dynamic

To further the conversation about financial literacy and decision-making, the following conceptual and system artefacts are presented to conceive logical and captivating design for gamification.

\section{FinCraft's conceptual framework}

Four foundational elements of the FinCraft conceptual framework are engagement, personalisation, motivation and adaptation.

Engagement: Literature highlights that familiarity, trust, and engagement are significant variables that could affect youth's motivation to adopt technology. The content must be somewhat familiar and relatable, so youth are inspired to subscribe to, and internalise the 
lessons of financial literacy enhancement. Figure 3 shows a simple model depicting how gamification could be further actualised for motivation through leveraging some level of familiarity, trust, and engagement in and with the platform.

Personalisation: Games are immersive and persuasive as they allow the user to embody characters they like in challenging scenarios. To enhance immersion and persuasion, personalisation is vital. Personalisation will be implemented through the personality archetyping system in addition to other characteristics.

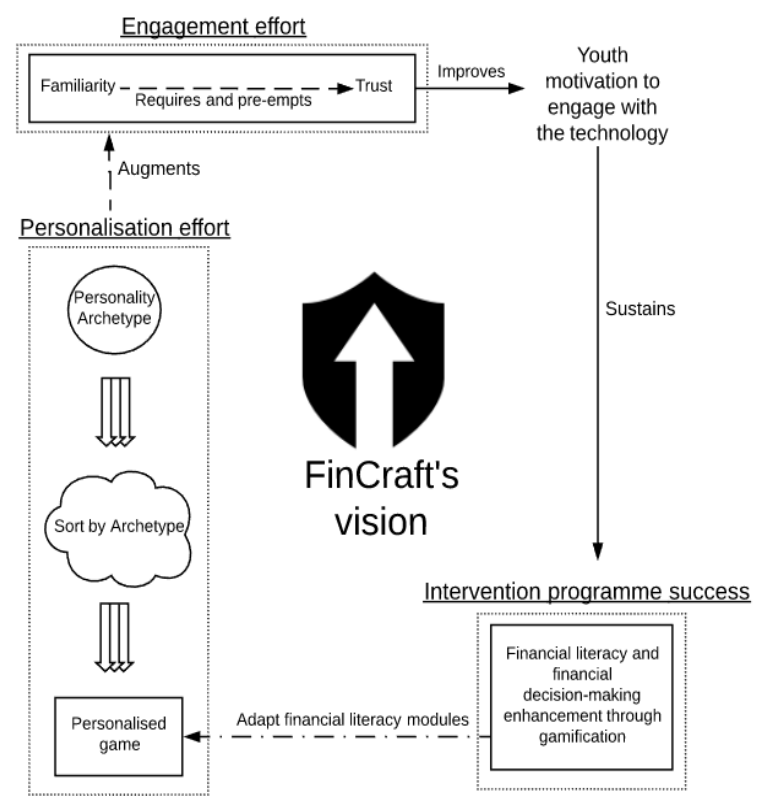

Figure 3. FinCraft's conceptual framework

Motivation: Through literature, we know that engagement, alongside the enhancing effect of personalisation, can sustain youth motivation in engaging with FinCraft technology. The main point in this vision is that the content released in the gaming platform should be familiar and trustworthy enough for it to be adapted for engagement.

Adaptation: Paramount to improving intervention programme success is adapting the financial literacy modules, in the personalisation of the games. The first step in doing this is to figure out each user's personality archetype. This enables us to form consistent and generalizable categories with which the financial modules can be applied. Huston's [26] four measures of financial literacy will be used as the overarching topical modules of the games. Games would then be created to satisfy a particular overarching module whilst specifying which target archetype it is addressing. For example, a game can be created for a 'knowledgeable hedonist' archetype under the 'financial literacy basics' category. By allowing many archetypes, and four financial modules, FinCraft can be quite customisable. Before such a vision can be executed, some form of categorisation and personalisation is vital, and we propose the personality octant tool in section 6 to support this.

\section{FinCraft's personality octant tool}

The design of the personality 'octant' tool originated from the triangulation of literature in financial literacy, education, personality and online money personality quizzes $[10,55,59,64,65,66,67]$. The rationale behind this synthesis is underpinned by the critical analysis of the current money personality quizzes surfacing online which usually characterizes individuals' spending and saving tendencies, and provides some outlook on improving upon these tendencies. It is observed that much of the results and analysis are not robustly grounded in literature. Most of the observations and characteristics produced are generalized characters, and amongst the several characterization styles, there are varying levels of abstraction to which they give perspectives. FinCraft's personality octant tool synthesizes similar elements from the personality quizzes and synthesizes it with literature in a way that is balanced and universal. Some money personality quizzes focus on the self, some focus on couples but rarely do they have an area to which financial literacy is considered as a main variable in the quizzes. Interestingly, youth and adults alike can take money personality quizzes focusing on the self and receive similar simplistic generalizations about their character. Much of Lusardi and Mitchell's work highlight the significant correlation between poverty and bad spending habits with low financial literacy $[34,35,36,38]$.

This artefact, created in consideration of Remmele [46], could lead FinCraft's personalisation effort. The personality octant tool is the primary means of personalisation for the user, as everyone is eventually categorised into a particular archetype. A key principle underlying the design is neutralising the individual value and utility of money. A neutral perspective is considered in contemplation of the three axes of financial literacy, spending preference and habit and reservedness. Whereby financial literacy is evaluated only on the awareness and understanding of cognitive financial knowledge sets. We allow for a neutral outlook on money by separating spending preference and habit and reservedness from individual utility. Here, we are able to model spender against investor without critiquing that either preference type is directly associated with an assumed financial literacy level. This avoids preliminary bias as it accounts for circumstances where a person can be proficient at their 
cognitive financial literacy knowledge and abilities, despite choosing to spend heavily and recklessly.

Habit and reservedness is an axis that would account for aggressiveness of financial decisions. In cases where people choose to invest or spend luxuriously, they can do so aggressively or conservatively. Utility and prime abstraction of money is ultimately unavoidable in order to progress financial literacy. We aim to equip the users with financial and decision-making literacy. Subsequent gamification elements are configured to drive current personal archetypal tendencies and characteristics towards more literate and secure financial decision-making. However, the design aims for neutrality and prevention of preliminary prejudice caused by spending preferences. As an octant, the artefact produces eight archetypes and the user is characterised into only one archetype. Figure 4 visualises the personality octant that combines the three axes of financial literacy, spending preference and habit and reservedness.

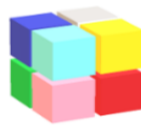

Figure 4. Octant
Each archetype will have attributes against each axis. Figure 5 portrays the link between the four financial modules and the eight archetypes and their descriptions. Figure 6 portrays the various affinities of the archetypes.

\begin{tabular}{|c|c|c|c|c|}
\hline $\begin{array}{l}\text { Archetype } \\
\text { Name }\end{array}$ & \begin{tabular}{|l} 
Financial \\
literacy \\
basics
\end{tabular} & Borrowing & $\begin{array}{l}\text { Protecting } \\
\text { assets }\end{array}$ & Investing \\
\hline $\begin{array}{l}\text { Knowledgeable } \\
\text { Hedonist }\end{array}$ & Little & Little & Little & Medium \\
\hline $\begin{array}{l}\text { Aggressive } \\
\text { Investor }\end{array}$ & Little & Medium & Medium & Little \\
\hline Money Hoarder & Strong & Strong & Strong & Little \\
\hline $\begin{array}{l}\text { Reckless } \\
\text { Consumer }\end{array}$ & Strong & Strong & Strong & Strong \\
\hline Simple Frugal & Strong & Medium & Medium & Medium \\
\hline $\begin{array}{l}\text { Educated Risk } \\
\text { Taker }\end{array}$ & Little & Medium & Medium & Medium \\
\hline Budgeteer & Little & Medium & Medium & Medium \\
\hline Scrooge & Strong & Strong & Strong & Strong \\
\hline
\end{tabular}

Figure 5. Module-archetype connection

\begin{tabular}{|c|c|c|c|c|}
\hline Colour Scheme & $\begin{array}{l}\text { Archetype } \\
\text { Name }\end{array}$ & $\begin{array}{l}\text { Financial } \\
\text { Literacy }\end{array}$ & $\begin{array}{l}\text { Habit and } \\
\text { reservedness }\end{array}$ & $\begin{array}{l}\text { Spending } \\
\text { preference }\end{array}$ \\
\hline Yellow & $\begin{array}{l}\text { Knowledgeable } \\
\text { Hedonist }\end{array}$ & High & $\begin{array}{l}\text { Aggressive/ } \\
\text { Impulsive }\end{array}$ & Spender \\
\hline Blue & $\begin{array}{l}\text { Aggressive } \\
\text { Investor }\end{array}$ & High & $\begin{array}{l}\text { Aggressive/ } \\
\text { Impulsive }\end{array}$ & $\begin{array}{l}\text { Investor/ } \\
\text { Saver }\end{array}$ \\
\hline Green & $\begin{array}{l}\text { Money } \\
\text { Hoarder }\end{array}$ & Low & $\begin{array}{l}\text { Aggressive/ } \\
\text { Impulsive }\end{array}$ & $\begin{array}{l}\text { Investor/ } \\
\text { Saver }\end{array}$ \\
\hline Red & $\begin{array}{l}\text { Reckless } \\
\text { Consumer }\end{array}$ & Low & $\begin{array}{l}\text { Careful/ } \\
\text { Conservative }\end{array}$ & $\begin{array}{l}\text { Investor/ } \\
\text { Saver }\end{array}$ \\
\hline Pink & Simple Frugal & Low & $\begin{array}{l}\text { Careful/ } \\
\text { Conservative }\end{array}$ & $\begin{array}{l}\text { Investor/ } \\
\text { Saver }\end{array}$ \\
\hline Cyan & $\begin{array}{l}\text { Educated Risk } \\
\text { Taker }\end{array}$ & High & $\begin{array}{l}\text { Careful/ } \\
\text { Conservative }\end{array}$ & $\begin{array}{l}\text { Investor/ } \\
\text { Saver }\end{array}$ \\
\hline Grey & Budgeteer & High & $\begin{array}{l}\text { Careful/ } \\
\text { Conservative }\end{array}$ & Spender \\
\hline Beige & Scrooge & Low & $\begin{array}{l}\text { Careful/ } \\
\text { Conservative }\end{array}$ & Spender \\
\hline
\end{tabular}

Figure 6. Archetype affinities
Huston's [26] measures of financial literacy provide the underlying structure for the modules that are available in FinCraft. Each will contain its collection of contextualised and personalised games, tackling key concepts within the module. Based on our synthesis, we have specifically identified the affinity of each archetype with the four financial modules.

\section{The Immersive, Personalised, Persuasive (IPP) FinCraft system framework}

The immersive, persuasive and personalised framework captures the visualisation of a real-life human player into a FinCraft archetype, and its corresponding game character equivalent. Essentially each archetype has a specific instantiation for each game variant. FinCraft is an open source platform with the configuration capability to add more games based on Huston's four financial modules and our FinCraft archetypes. This is such that games can be created to focus on financial modules from the perspective of different archetypes e.g. investing for knowledgeable hedonists. The framework (Figure 7) shows appreciation, integration and overall rework of Argyris and Schön's loops of learning models, Romme and Van Witteloostuijn's triple-loop learning adaptation, and Bateson's levels of learning framework $[1,19,57]$.

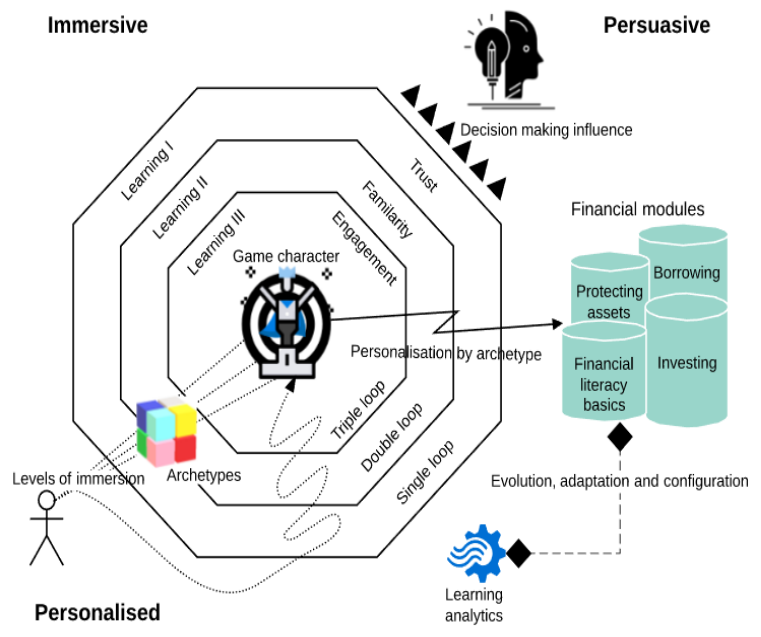

Figure 7. The IPP FinCraft framework

Immersive: Along with the synthesis done in our literature review, the IPP framework further argues that as the user delves deeper into the game realm, so does their ability and propensity to construct knowledge. Essentially their level of immersion is increased as they become more intertwined within the interactions of the game realm. The rings of the structure represent the levels of immersion. The outer levels represent lower levels of learning consciousness whilst applying more 
simplistic loop learning models i.e. single loop learning. However, as we delve deeper into FinCraft, the level of immersion grows, so does its immersion to higher orders of learning consciousness (from learning I to learning II and learning III) and deeper learning loops (from single loop to double loop and triple loop).

Personalised: Personalisation occurs mainly through the initial categorisation of the personality octant, and the subsequent adaptation of a game based on an archetype and a specific financial module. The personalisation effect and the leading charge of the personality octant is summarised by the aforementioned conceptual artefacts. The IPP framework is further useful for highlighting the configurative effect of learning analytics. Within FinCraft, we envision allowing for some level of learning analytics to continuously improve upon the personal and archetypal needs of the user. Using real time data and analytics to configure and adapt gaming mechanics to the optimum level of financial literacy enhancement is an ideal vision for FinCraft.

Persuasive: The persuasive factor is a culminating result of all immersive and personalisation factors in FinCraft. Once the young user is engaged within the game realm, as a game character, familiarity and trust is easy to come by. As such, this will allow youth to be persuaded into secure and effective financial decisionmaking habits. FinCraft is persuasive in the sense that it works on familiar and trustworthy content for youth so that they can be eased towards learning financial content and adopting secure financial decision-making.

Learning analytics and gamification: Learning analytics is a central component that brings together and improves all three tenets (persuasion, personalisation, immersion) in the gamification system framework. IPP stands on Koivisto \& Hamari's research [30] underlining the importance of improving the consistency and coherence of gamification research models. FinCraft firstly attempts to affirm the vision that gamification will work, and will be effective in improving the motivation and adaptation of financial literacy. Furthermore, FinCraft envisions that gamification features can be boosted by learning analytics. Through completion of financial literacy modules the following gamification features can be obtained: points, badges and leader board positions. Chatti et al [10] summarises that data collection, preprocessing, analytics, action, and post-processing allows for the possibility of evaluating scoring metrics, benchmarking and design iterations, which can all be useful in further enhancing the immersion, persuasion and personalisation gaming features [10].

Learning analytics is vital for implementing space, mission and character adaptations [3]. FinCraft envisions a dynamic playing environment that grows alongside the player. Financial literacy games will have changing difficulty depending on the level of skill accrued through gameplay. Additionally, access to overall gaming functionality is bypassed the higher the user level. Of course, learning analytics will be working behind the game as user skill and points are gained. The overall dynamic allows for the optimisation of level progression in order to maximize the value of financial literacy enhancement, as well as the player's coverage of the whole game. Character adaptation is also monitored by learning analytics through a back-end leader board system that evaluates the rank and module level to which the player belongs to. For every financial literacy module, there are corresponding badge achievements and leader board systems of which the player can achieve through successful gameplay.

\section{FinCraft system architecture}

The system architecture that binds personalisation into the immersive and persuasive nature of FinCraft is illustrated in Figure 8. Essentially, personal user input is taken in as the foundation for understanding user requirements. Using the personality octant, the FinCraft's conceptual framework, and the IPP system framework, FinCraft is better able to customise and personalise the game content and difficulty to the exact needs of the user. The architecture focuses on the decision maker/user. The user is initially prompted to answer a personality questionnaire. The questionnaire pre-empts the sorting system that occurs within the recommendation server, the user is thus sorted into one of the 8 archetypes of the personality octant. This record is then stored in the learning management system which contains a compilation of the four financial modules (i.e. financial basics, borrowing, protecting assets and investing); these are further subdivided by their corresponding personality archetype. It is such that a 'knowledgeable hedonist' along with the others, would have its own database in the server separate from the other octant archetypes.

Game content developers are able to configure the financial modules available in the game by interacting with the learning management system and tailoring the content based on the specific personalities or characteristics that the archetype suggests. Subsequently, all configurations in the modules will directly affect the base game of FinCraft. Several levels and custom map scenarios are augmented within the base game whereby a certain financial literacy concept is studied. For example, investment mechanics can be studied by simulating a 'wall street' situation where the player is then placed in investing situations. The rationale behind each level's configurability is to allow 
some level of personalized familiarity within the learning. This personalization occurs in the interaction between the recommendation server and the base game. Game developers can add content to each archetypal database and through the recommendation server, the base game will have access to the corresponding game updates and additions. In essence, the recommendation server will act as a gateway for future expansion packages.

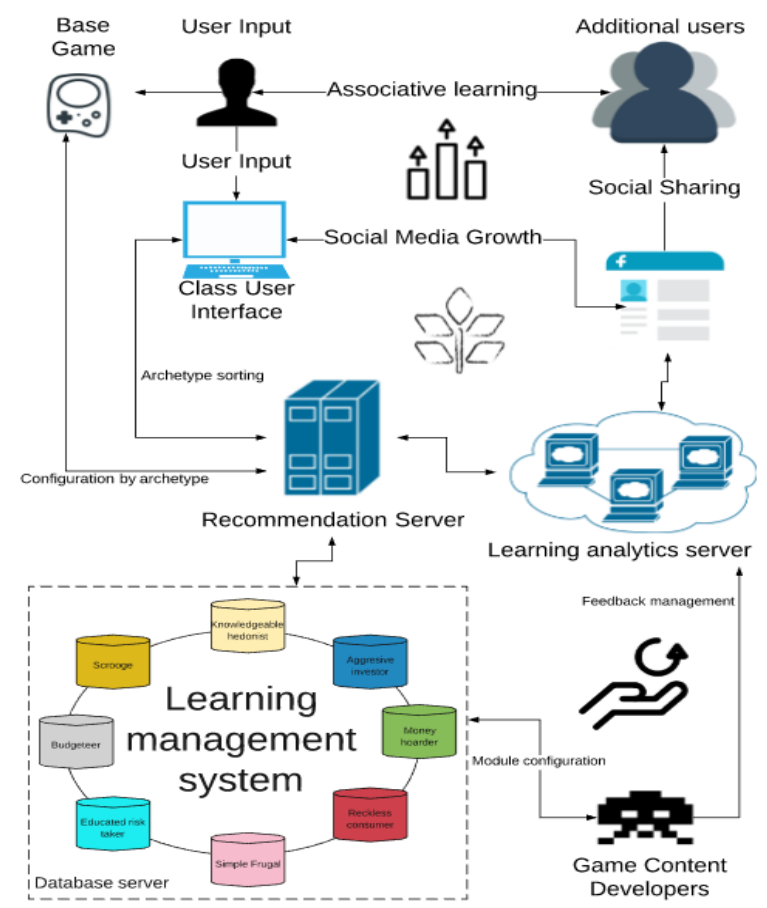

Figure 8. The IPP FinCraft architecture

FinCraft also incorporates learning analytics, whereby statistics, tendencies and common gaming characteristics of each archetype are logged and analysed. The rationale behind this is to truly affirm the separation of these archetypes into its own individual type. Game developers' ability to access the learning analytics server whereby scores, results and other feedback are managed, help in determining the most effective way of gamifying financial literacy for each archetype. Using these results game developers can configure the modules in the learning management system which will then be implemented by the recommendation server onto the base game. Moreover, the learning analytics server is also directly connected to social media and a web where the scores, results and feedback can be publicised for marketing and associative learning purposes. The class user interface will have its augmentation to an embedded social media platform to enable social sharing of results and achievements with other users. Additional users can then participate in the financial literacy games making the overall experience more collaborative. As a result, some level of associative learning is achieved from the main user and the subsequent interaction with other players within a specific configuration of FinCraft.

FinCraft will promote good saving habits and enhance financial literacy, whereby, each archetypes' flaws in financial decision-making will be addressed by the game's configurability. For example, 'knowledgeable hedonists' who are characterized to be financially literate, but are susceptible to bad spending habits, will then be more oriented towards habit reformation games - where the games are more so to affirm good spending habits over unsustainable ones. Archetypes described to more financially illiterate would expect higher levels of financial education within the games available in FinCraft.

\section{Conclusion}

Financial literacy is important for everyone to shape their future, despite the fact that we do not have good vehicle to deliver them effectively to our young people. In this paper, we argue for an immersive personalised persuasive serious game platform that we call FinCraft. In doing so, we pay particular attention to the existing biases among financial literacy studies and educational instruments. Throughout the paper, we present the conceptual framework, the personality octant, the IPP system framework and the system architecture of FinCraft. We believe FinCraft could promote good saving habits and the improvement of financial literacy of young decision-makers.

\section{References}

[1] Argyris, Ch., and D.A. Schön, "Organizational Learning: A Theory of Action Perspective", Reis(77/78), 1997, pp. 345-348.

[2] Atkinson, A., S. McKay, S. Collard, and E. Kempson, "Levels of financial capability in the UK", Public Money and Management 27(1), 2007, pp. 29-36.

[3] Bakkes, S., C.T. Tan, and Y. Pisan, "Personalised gaming: a motivation and overview of literature", Proceedings of The 8th Australasian Conference on Interactive Entertainment Playing the System - IE '12, ACM Press (2012), 1-10.

[4] Bang, J., and C. Dalsgaard, "Rethinking e-learning: Shifting the focus to learning activities", In Enhancing learning through technology. IGI Global, 2006, 184-202.

[5] Bernheim, B.D., D.M. Garrett, and D.M. Maki, "Education and saving:: The long-term effects of high school financial curriculum mandates", Journal of public Economics 80(3), 2001, pp. 435-465.

[6] Berti, A.E., "Sketching a Possible Learning Progression 
for the Cognitive Component of Financial Education in the Broader Context of Economic Education", In C. Aprea, E. Wuttke, K. Breuer, et al., eds., International Handbook of Financial Literacy. Springer Singapore, Singapore, 2016, 515-530.

[7] Boendermaker, W.J., M. Boffo, and R.W. Wiers, "Exploring elements of fun to motivate youth to do cognitive bias modification", Games for Health Journal 4(6), 2015, pp. 434-443.

[8] Buckley, P., and E. Doyle, "Gamification and student motivation", Interactive learning environments 24(6), 2016, pp. 1162-1175.

[9] Burke, J.W., M.D.J. McNeill, D.K. Charles, P.J. Morrow, J.H. Crosbie, and S.M. McDonough, "Optimising engagement for stroke rehabilitation using serious games", The Visual Computer 25(12), 2009, pp. 1085.

[10] Chatti, M.A., A.L. Dyckhoff, U. Schroeder, and H. Thüs, "A reference model for learning analytics", International Journal of Technology Enhanced Learning 4(5-6), 2013, pp. 318-331.

[11] Cohen, W.M., and D.A. Levinthal, "Absorptive Capacity: A New Perspective on Learning and Innovation", Administrative Science Quarterly 35(1), 1990, pp. 128.

[12] Cole, S., T. Sampson, and B. Zia, "Prices or knowledge? What drives demand for financial services in emerging markets?", The journal of finance 66(6), 2011, pp. 19331967.

[13] Cummings, J.L., and B.-S. Teng, "Transferring R\&D knowledge: the key factors affecting knowledge transfer success", Journal of Engineering and technology management 20(1-2), 2003, pp. 39-68.

[14] Deterding, S., "Gamification: designing for motivation", interactions 19(4), 2012, pp. 14-17.

[15] Ellis, H.C., The transfer of learning., Macmillan, Oxford, England, 1965.

[16] Farsagli, S., U. Filotto, and F. Traclò, "Educating People About Finance and Economics. Approaching Curriculum Design: An Italian Experience", In C. Aprea, E. Wuttke, K. Breuer, et al., eds., International Handbook of Financial Literacy. Springer Singapore, Singapore, 2016, 531-543.

[17] Follett, M.P., 1868-1933, H.C. Metcalf, 1867-, L.F. (Lyndall F. Urwick, and 1891-1983, "Dynamic administration", 1942.

[18] Gefen, D., "E-commerce: the role of familiarity and trust", Omega 28(6), 2000, pp. 725-737.

[19] Georges L. Romme, A., and A. van Witteloostuijn, "Circular organizing and triple loop learning", Journal of Organizational Change Management 12(5), 1999, pp. 439454.

[20] Hanus, M.D., and J. Fox, "Assessing the effects of gamification in the classroom: A longitudinal study on intrinsic motivation, social comparison, satisfaction, effort, and academic performance", Computers \& Education 80, 2015, pp. 152-161.
[21] Harlow, H.F., and R.R. Zimmermann, "Affectional Responses in the Infant Monkey”, Science 130(3373), 1959, pp. 421-432.

[22] Heath, J.A., "Youth Financial Literacy in the United States: A Patchwork Approach”, In C. Aprea, E. Wuttke, K. Breuer, et al., eds., International Handbook of Financial Literacy. Springer Singapore, Singapore, 2016, 369-380.

[23] Hilgert, M.A., J.M. Hogarth, and S.G. Beverly, "Household financial management: The connection between knowledge and behavior", Fed. Res. Bull. 89, 2003, pp. 309.

[24] Hill, A.T., and C.J. Asarta, "Gender and Student Achievement in Personal Finance: Evidence from Keys to Financial Success", In C. Aprea, E. Wuttke, K. Breuer, et al., eds., International Handbook of Financial Literacy. Springer Singapore, Singapore, 2016, 545-567.

[25] Huang, W.H.-Y., and D. Soman, "Gamification of education”, Research Report Series: Behavioural Economics in Action, Rotman School of Management, University of Toronto, 2013.

[26] Huston, S.J., "Measuring financial literacy", Journal of Consumer Affairs 44(2), 2010, pp. 296-316.

[27] Johnson, E., and M.S. Sherraden, "From Financial Literacy to Financial Capability smong Youth", J. Soc. \& Soc. Welfare 34, 2007, pp. 119.

[28] Knoote, F.E., G. Partington, and J. Penner, "Children and Youth as Economic Citizens: Working Towards an Integrated Financial Education Approach", In C. Aprea, E. Wuttke, K. Breuer, et al., eds., International Handbook of Financial Literacy. Springer Singapore, Singapore, 2016, 193-211.

[29] Koh, N.K., "Approaches to Teaching Financial Literacy: Evidence-Based Practices in Singapore Schools", In C. Aprea, E. Wuttke, K. Breuer, et al., eds., International Handbook of Financial Literacy. Springer Singapore, Singapore, 2016, 499-513.

[30] Koivisto, J., and J. Hamari, "The rise of motivational information systems: A review of gamification research", International Journal of Information Management 45, 2019, pp. 191-210.

[31] Kotlikoff, L.J., and B.D. Bernheim, "Household financial planning and financial literacy", Essays on saving, bequests, altruism, and life-cycle planning, 2001, pp. 427478.

[32] Loerwald, D., and A. Stemmann, "Behavioral Finance and Financial Literacy: Educational Implications of Biases in Financial Decision Making”, In C. Aprea, E. Wuttke, K. Breuer, et al., eds., International Handbook of Financial Literacy. Springer Singapore, Singapore, 2016, 25-38.

[33] Lusardi, A., and O.S. Mitchell, Financial literacy and planning: Implications for retirement wellbeing, National Bureau of Economic Research, 2011.

[34] Lusardi, A., and O.S. Mitchell, "Financial literacy around the world: an overview", Journal of pension economics \& finance 10(4), 2011, pp. 497-508. 
[35] Lusardi, A., and O.S. Mitchell, "The economic importance of financial literacy: Theory and evidence", Journal of economic literature 52(1), 2014, pp. 5-44.

[36] Lusardi, A., O.S. Mitchell, and V. Curto, "Financial literacy among the young", Journal of consumer affairs 44(2), 2010, pp. 358-380.

[37] Lusardi, A., D.J. Schneider, and P. Tufano, Financially fragile households: Evidence and implications, National Bureau of Economic Research, 2011.

[38] Lusardi, A., and P. Tufano, "Debt literacy, financial experiences, and overindebtedness", Journal of Pension Economics \& Finance 14(4), 2015, pp. 332-368.

[39] Mansfield, E., J. Rapoport, A. Romeo, S. Wagner, and G. Beardsley, "Social and private rates of return from industrial innovations", The quarterly Journal of economics 91(2), 1977, pp. 221-240.

[40] Mayer, R.E., "Multimedia learning”, In Psychology of learning and motivation. Elsevier, 2002, 85-139.

[41] Michael, D.R., and S.L. Chen, Serious Games: Games That Educate, Train, and Inform, Muska \& Lipman/PremierTrade, 2005.

[42] Moore, M.G., and G.G. Kearsley, Distance education: A system view, Wadsworth, 1996.

[43] Pang, M.F., "Enhancing the Financial Literacy of Young People: A Conceptual Approach Based on the Variation Theory of Learning", In C. Aprea, E. Wuttke, K. Breuer, et al., eds., International Handbook of Financial Literacy. Springer Singapore, Singapore, 2016, 587-602.

[44] Peffers, K., T. Tuunanen, M.A. Rothenberger, and S. Chatterjee, "A design science research methodology for information systems research", Journal of management information systems 24(3), 2007, pp. 45-77.

[45] Peña, P.A., "Personality and Financial Culture: A Study of Mexican Youths", In C. Aprea, E. Wuttke, K. Breuer, et al., eds., International Handbook of Financial Literacy. Springer Singapore, Singapore, 2016, 465-493.

[46] Remmele, B., "Financial Literacy and Financial Incomprehensibility", In C. Aprea, E. Wuttke, K. Breuer, et al., eds., International Handbook of Financial Literacy. Springer Singapore, Singapore, 2016, 39-55.

[47] Ritterfeld, U., M. Cody, and P. Vorderer, Serious games: Mechanisms and effects, Routledge, 2009.

[48] Roblyer, M.D., Integrating educational technology into teaching, Upper Saddle River, N.J.: Merrill/Prentice Hall c2003., Upper Saddle River, N.J., 2003.

[49] Seaborn, K., and D.I. Fels, "Gamification in theory and action: A survey", International Journal of human-computer studies 74, 2015, pp. 14-31

[50] Siemens, G., "Learning analytics and educational data mining: towards communication and collaboration", pp. 3 .

[51] Simon, H.A., "From substantive to procedural rationality", In T.J. Kastelein, S.K. Kuipers, W.A. Nijenhuis and G.R. Wagenaar, eds., 25 Years of Economic Theory:
Retrospect and prospect. Springer US, Boston, MA, 1976, 65-86.

[52] Siu, E.Y.N., and N.K. Koh, "A Design-Based Intervention Approach to the Development of a Financial Literacy Interactive Learning Journey for Youths in Singapore", In C. Aprea, E. Wuttke, K. Breuer, et al., eds., International Handbook of Financial Literacy. Springer Singapore, Singapore, 2016, 569-585.

[53] Smith, B.L., and J.T. MacGregor, What is collaborative learning, Washington, 1992.

[54] Sorensen, E.K., and D. Ó Murchú, Enhancing learning through technology, Hershey, PA : Information Science Pub. c2006., Hershey, PA, 2006.

[55] Susi, T., M. Johannesson, and P. Backlund, Serious games: An overview, Institutionen för kommunikation och information, 2007.

[56] Teece, D.J., "Multinational corporation and the resource cost of international technology transfer", 1976.

[57] Tosey, P., Bateson's Levels Of Learning: a Framework For Transformative Learning?, 2019.

[58] Walsh, J.P., and G.R. Ungson, "ORGANIZATIONAL MEMORY", Academy of Management Review 16(1), 1991, pp. 57-91.

[59] Wouters, P., C. Van Nimwegen, H. Van Oostendorp, and E.D. Van Der Spek, "A meta-analysis of the cognitive and motivational effects of serious games.", Journal of educational psychology 105(2), 2013, pp. 249.

[60] Xu, L., and B. Zia, Financial literacy around the world: an overview of the evidence with practical suggestions for the way forward, The World Bank, 2012.

[61] Yee, N., "Motivations for play in online games", CyberPsychology \& behavior 9(6), 2006, pp. 772-775.

[62] Yeo, J.K.K., "Infusing Financial Literacy in Primary Mathematics: A Proposed Framework for Instruction", In C. Aprea, E. Wuttke, K. Breuer, et al., eds., International Handbook of Financial Literacy. Springer Singapore, Singapore, 2016, 603-616.

[63] Digital diversions: youth culture in the age of multimedia, UCL Press, London, 1998.

[64] "Mind on my money: The Spinoff takes Nigel Latta's money personality quiz", The Spinoff, 2018. https://thespinoff.co.nz/business/23-04-2018/mind-on-mymoney-the-spinoff-takes-nigel-lattas-money-personalityquiz/

[65] "5 Money Personalities - The Money Couple", https://themoneycouple.com/resources/5-moneypersonalities/

[66] "Money personality quiz | LifeSkills", Barclays Life Skills. http://barclayslifeskills.com:8081/i-want-to-get-togrips-with-money-and-my-payslip/school/moneypersonality-quiz

[67] "Take the Moneyharmony Quiz! | Moneyharmony", https://www.moneyharmony.com/moneyharmony-quiz 